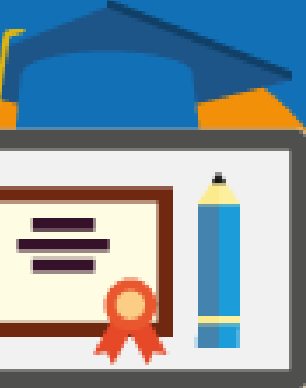

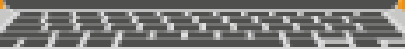

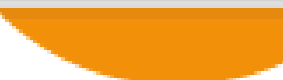

\title{
ACEITAÇÃO DO USO DE SLIDES COMO RECURSO DIDÁTICO POR ALUNOS DO ENSINO SUPERIOR
}

\author{
Rosineide da Silva Bonilla \\ (UFGD) e-mail: rosineide.silva1981@gmail.com
}

Jonas Martins Santos

(UNEB) e-mail: jonasmartins.ads@,gmail.com

Tânia Jucilene Vieira Vilela

(UFGD) e-mail: rtrvilela4@gmail.com

\begin{abstract}
RESUMO: O trabalho traz discussões sobre a aceitação dos alunos (as) no uso dos slides como recurso didático. Abordaremos discussões acerca do âmbito educacional e as tecnologias digitais, com vistas a contribuir com a relação entre professor, aluno no ensino superior nos cursos de tecnologia das universidades UNEB e UFGD presenciais e a distância. Dessa forma, a pesquisa bibliográfica inicia-se por meio dos conceitos sobre a importância das tecnologias da informação e comunicação no meio educacional. A metodologia utilizada será de cunho bibliográfico e pesquisa quantitativa-qualitativa aos discentes, visando a possibilidade de chegar há discussões que possam responder nossos questionamentos sobre a problemática levantada em nossa pesquisa, de como está sendo a aceitação do uso das ferramentas tecnológicas como mediação pedagógica no ensino superior. Para o embasamento teórico utilizamos KENSKI (2012), SOUZA; LINHARES (2012) e MENEGAZ (2016) que destacam sobre o tema abordado, enfocando questões significativas para nossas reflexões na área educacional pedagógica por meio da tecnologia no que compete o ensino-aprendizagem e seus recursos. Os resultados serão de grande valia para que possamos praticar essas questões sobre a era digital e suas ferramentas que poderão ser usadas com mais propriedade nas aulas dos futuros profissionais da educação.
\end{abstract}

Palavras-chave: Slides; Educação superior; Mediação pedagógica.

\section{INTRODUÇÃO}

As tecnologias da informação e comunicação (TIC) estão transformando vários segmentos da sociedade contemporânea, dentre eles a educação. Essa passou por diversas mudanças desde a inserção do uso de computadores nas práticas de ensino e no processo de 


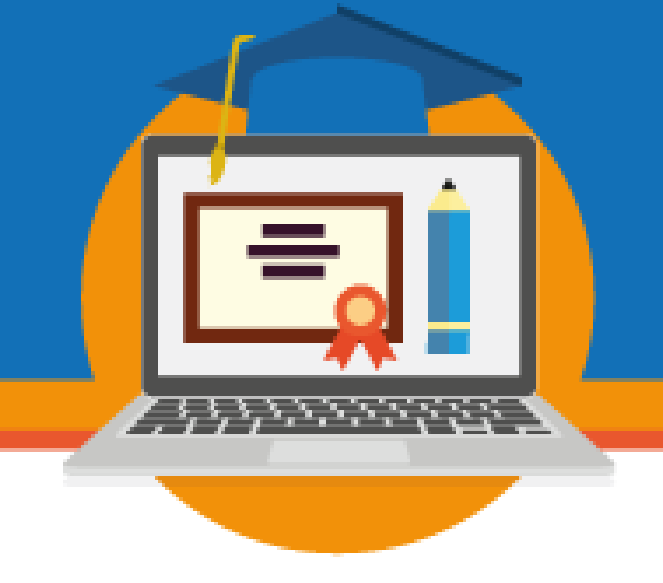

construção do conhecimento. Hoje, há questionamentos em relação ao uso de tecnologias digitais na dinâmica das aulas, quanto à forma como os professores usam os recursos disponíveis e se os mesmos são utilizados devidamente para a aprendizagem dos conteúdos em sala de aula.

Um recurso que se popularizou como recurso didático foram os slides, difundido pelo uso do aplicativo PowerPoint da empresa Microsoft ${ }^{1}$. O uso de novos recursos foi se ampliando, mas o slide ainda continua a ser usado por muitos profissionais para a mediação no ensino das escolas e também no ensino superior.

Anteriormente, os slides eram utilizados através de retroprojetor (aparelho óptico que permite projetar numa parede ou tela uma imagem), sendo possível apenas apresentar textos e imagens estáticas. No entanto, esse quadro foi alterando com o surgimento do datashow (um retroprojetor eletrônico), aliado aos computadores e programas como o PowerPoint possibilitou-se dinamizar as apresentações agora com textos, imagens, sons e vídeos combinados aos efeitos de transições (mudanças de um slide para outro) e animações nos mesmos. Outro avanço com a utilização desses programas foi a praticidade na modelagem e criação desse recurso. $\mathrm{O}$ trabalho de criação desses slides tornou-se mais simples devido à qualidade da usabilidade dos aplicativos para a mediação do conhecimento proposto.

Dessa forma, os professores começaram a planejar suas aulas com esse recurso adicional, embora muitos não aproveitassem as possibilidades disponíveis nesses aplicativos e preferissem simplesmente apresentá-los usando telas estáticas, contendo excessivos textos e imagens. É nessa ação do professor em sala de aula, e no uso feito dos suportes tecnológicos que se encontram a sua disposição, relacionando o conhecimento a ser desenvolvido e a forma como são usadas às tecnologias disponíveis no ensino/aprendizado do aluno (KENSKI, 2012, p.19).

\footnotetext{
${ }^{1}$ Empresa transnacional americana. Consulta em: https://pt.wikipedia.org/wiki/Microsoft. Acesso em 10 jan. 2018.
} 


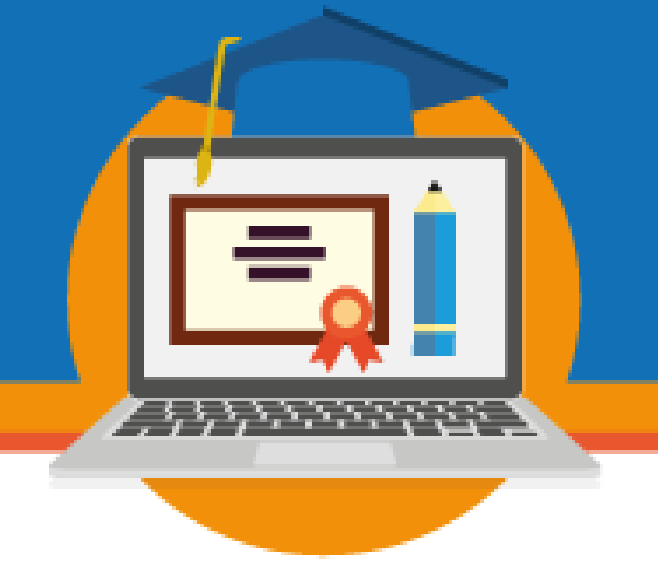

Perpassando o olhar para essas práticas de uso dos slides em sala de aula, é que surge a necessidade de investigar como os alunos estão avaliando o uso desse recurso e se a forma como os professores têm utilizado está sendo eficiente para o ensino e aprendizado dos novos conhecimentos nos cursos presenciais e a distância das duas universidades, Universidade do Estado da Bahia (UNEB) e Universidade Federal da Grande Dourados (UFGD).

Nesse caso específico, entrelaçam as práticas docentes com os conteúdos, a apropriação de informações e a consequente valorização dos mais diversos ambientes e sistemas de aprendizagem. Com isso, comprova-se que o ensinar/aprender não estão separados e que esta relação deve funcionar de forma mais criativa e dinâmica, e sem perder de vista a racionalidade humana e a mediação das tecnologias da informação e comunicação.

Deste modo, esta pesquisa teve como objetivo analisar a aceitação dos discentes no uso de slides como recurso didático no ensino superior. Para tanto propomos avaliar, por meio de um questionário online enviado a esses estudantes do ensino superior das instituições citadas, a aceitação pela forma como os professores usam os recursos citados nas aulas.

\section{JUSTIFICATIVA}

$\mathrm{O}$ interesse pela pesquisa e a investigação iniciou-se por estarmos envolvidos no meio educacional em cursos de tecnologia e educação a distância, preocupados em como a aprendizagem está sendo mediada em seus recursos didáticos, em especial, pelo uso dos slides, e como está sendo vista pelos discentes no ensino superior. Nesse cenário, surge à necessidade de tecer reflexões sobre o uso didático por meio da tecnologia e como está sendo aplicado pelos profissionais/mediadores. E, ainda, como esse uso está sendo apreciado pelos discentes que estão cursando cursos tecnológicos presenciais e a distância nas universidades UNEB e UFGD.

Por conseguinte, como proposta norteadora desta investigação, tencionamos um olhar mais atento as pesquisas e discussões sobre os recursos da tecnologia, os quais não são novos, mas que devem ser revisitados para melhor contribuir para o uso didático, e um ensino de 


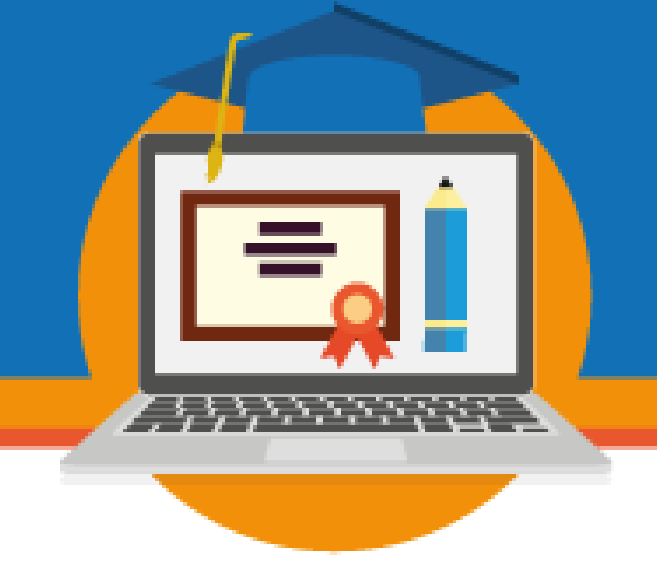

qualidade aos futuros profissionais da educação, de forma relevante para ampliar as reflexões sobre tecnologias e mediações pedagógicas no ensino superior.

\section{FUNDAMENTAÇÃO TEÓRICA}

Neste contexto educacional em que os recursos didáticos exercem uma significativa importância para a aprendizagem dos alunos, é que as metodologias são ações que devem ser bem planejadas, pois:

Na era da informação, comportamentos, práticas, informações e saberes se alteram com extrema velocidade. Um saber ampliado e mutante caracteriza o estágio do conhecimento na atualidade. Essas alterações refletem-se sobre tradicionais formas de pensar e fazer educação. Abrir-se para novas educações, resultantes de mudanças estruturais nas formas de ensinar e aprender possibilitadas pela atualidade tecnológica, é o desafio a ser assumido por toda a sociedade (KENSKI, 2012, p.41).

$\mathrm{O}$ olhar sobre esses recursos didáticos vem agregar novos questionamentos que os alunos (aqui um recorte dos alunos do ensino superior) possam pontuar como está sendo a aceitação sobre os slides em sala de aula. Dessa forma, "as tecnologias digitais criaram um novo cenário para o pensamento, a aprendizagem e a comunicação humana, transformando a natureza das ferramentas disponíveis para pensar, agir e se expressar" (DUSSEL apud MENEGAZ, 2016, p.64). As tecnologias digitais e essas ferramentas vão agregar ações que o grupo irá precisar para complementação de suas tarefas com êxito.

A tecnologia de informação é uma ferramenta essencial para disseminação do ensino em nível mundial, haja vista que, essa modalidade tende a universalizar as oportunidades alcançando um quantitativo cada vez maior de pessoas com melhor qualificação e eficiência.

Considerando a temática da tecnologia, quando nos referimos ao termo "tecnologia" estamos utilizando uma palavra para descrever algo ou alguma coisa, deste modo podemos conceituá-la como:

Palavra usada para designar coisas muito diferentes entre si. Como termo de uso comum, ela pode significar a habilidade da pessoa manipular instrumentos de sorte a obter resultados ou produtos desejáveis decorrentes de ações apropriadas para transformar objetos - casos em que tecnologia é igualada à técnica e aos instrumentos confeccionados para o homem executar ações específicas, 
Neste sentido, é pertinente questionar se o profissional que trabalha e desenvolve as atividades docentes se preocupa em não apenas aplicar um conteúdo, mas sim planejar e desenvolver com olhar mais inovador, por se tratar de tecnologia, e com ferramentas/recursos para a aprendizagem mais dinâmica em sala de aula. $\mathrm{Na}$ visão de alguns teóricos a aprendizagem somente vai ser autônoma se despertar no aprendiz a sua curiosidade de instruirse no ensinamento. Para tanto:

\begin{abstract}
A formação de qualidade dos docentes deve ser vista em um amplo quadro de complementação às tradicionais disciplinas pedagógicas e que inclui, entre outros, um razoável conhecimento de uso do computador, das redes e de demais suportes midiáticos [...] em variadas e diferenciadas atividades de aprendizagem. É preciso saber utilizá-los adequadamente. Identificar quais as melhores maneiras de usar as tecnologias para abordar um determinado tema ou projeto específico ou refletir sobre eles, de maneira a aliar as especificidades do "suporte" pedagógico [...] ao objetivo maior da qualidade de aprendizagem dos alunos (KENSKI, 2008 apud KENSKI, 2012, p.4).
\end{abstract}

$\mathrm{Na}$ visão de Kenski (2012), é preciso adequar às formas tecnológicas de ensino aprendizagem e seus suportes técnicos, ou seja, cabe ao professor revisitar suas metodologias em sala de aula. Os docentes serão os mediadores desses conteúdos e devem se preocupar com os recursos didáticos de multimídias com mais cautela e aprimoramento na área educacional.

\title{
METODOLOGIA
}

A pesquisa em questão é caracterizada como qualitativa, a partir da observação direta extensiva, utilizando-se de questionários com perguntas objetivas e abertas como instrumento de coleta de dados. Na pesquisa qualitativa "“...] o pesquisador procura reduzir a distância entre a teoria e os dados, entre o contexto e a ação, usando a lógica da análise fenomenológica, isto é, da compreensão dos fenômenos pela sua descrição e interpretação" (TEIXEIRA, 2016, p.137), pois a experiência pessoal desse ator que pesquisa o seu objeto de estudo é de suma importância para as análises e em conjunto com os dados coletados em sua pesquisa.

Os sujeitos da pesquisa foram 67 (sessenta e sete) discentes dos cursos de Licenciatura e Bacharelado das universidades UNEB e da UFGD e após a coleta de dados, estes foram tabulados, organizados e analisados de forma descritiva (MORGADO, 2012, p. 63), "o estudo 


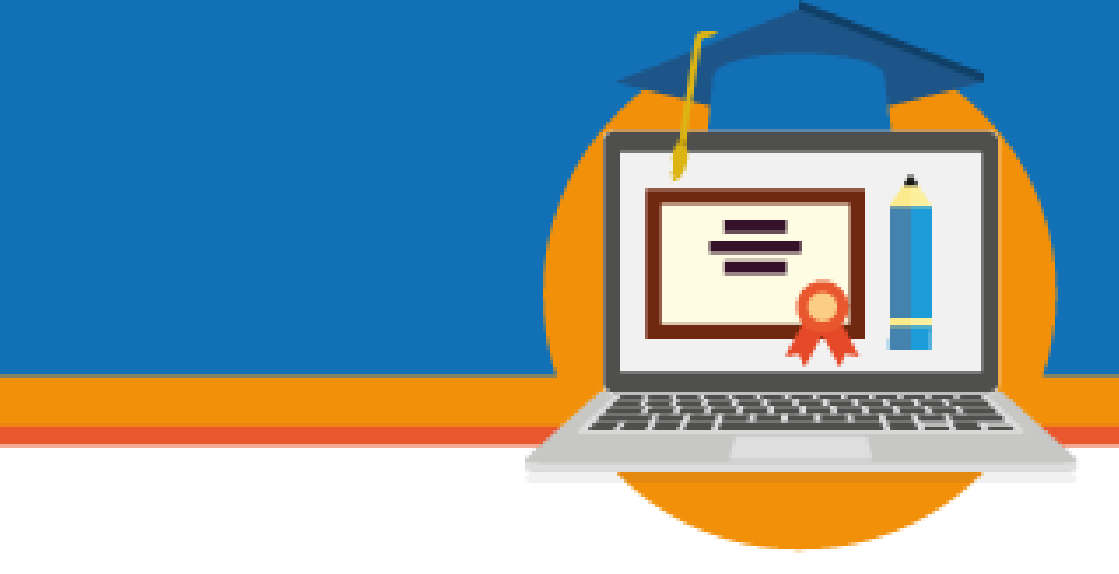

de caso é um processo de investigação empírica que permite estudar fenômenos no seu contexto real".

Nessa pesquisa foi usado um rigor contrário ao da precisão numérica aos fenômenos não sujeitos a estudos quantitativos, esses fenômenos apresentam dimensões pessoais, mais apropriados na pesquisa dessa abordagem. Os estudos assim realizados apresentam significados mais relevantes para os sujeitos envolvidos e para o campo de pesquisa ao qual o estudo desses fenômenos pertence (RAMPAZZO, 2005).

Quanto à técnica de pesquisa foi utilizado o questionário que como sugere Severino (2007, p. 124) foi aplicado um "[...] conjunto de questões, sistematicamente articuladas, que se destinam a levantar informações escritas por parte dos sujeitos pesquisados, com vistas a conhecer a opinião dos mesmos sobre os assuntos em estudo".

As questões foram objetivas e abertas suscitando respostas igualmente objetivas, evitando provocar dúvidas (SEVERINO, 2007). Nesses questionários constavam 10 (dez) perguntas sobre aceitação do uso de slides em aulas do ensino superior.

De posse dos dados coletados, revisados e selecionados, iniciou-se o processo de organização, usando como formato a tabulação, sendo os dados obtidos transferidos para tabelas, numa planilha eletrônica, a fim de serem observados e submetidos à análise (CELLARD, 2008, p.266).

\section{RESULTADOS E DISCUSSÕES}

Para finalizarmos nossa investigação e chegarmos à solução e/ou reflexões sobre a problemática desta investigação que foi, por meio de um questionário online com dez questões

\section{SEMINÁRIO DE EDUCAÇÃO A DISTÂNCIA}

EaD na região Centro-Oeste: Institucionalização, Limites e Potencialidades

12 a 14 de abril de 2018 - Campo Grande/MS 


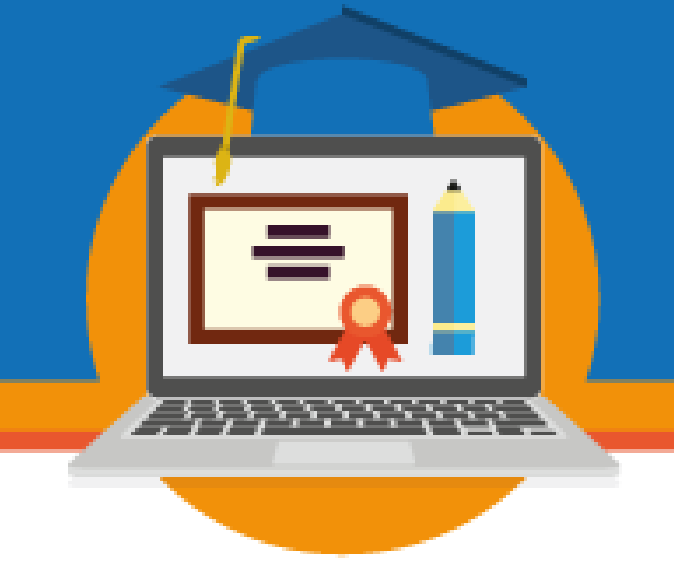

objetivas e uma descritiva, para que pudéssemos ter uma dimensão das opiniões dos discentes, no que se relacionam aos meios didáticos multimídias slides em sala de aula no ensino superior.

As questões foram direcionadas acerca do uso dos slides em sala de aula no ensino superior, ou seja, questionamentos que pudessem levar esses discentes a nos dar indícios de como essa didática está sendo desenvolvida para a mediação da aprendizagem. Assim, obtivemos um quantitativo de 67 (sessenta e sete) respostas dentre as duas universidades investigadas.

As perguntas que compõem esse questionário da primeira à quarta questão estavam voltadas para a identificação desses discentes, sobre a instituição em que estão inseridos UNEB e/ou UFGD. Além de, direcionarmos as respostas para sabermos em que semestre estão estudando, que idade tem esse público, e se seus professores utilizam esse recurso/ferramenta para a aprendizagem dos seus alunos em sala de aula.

Seguindo com os questionamentos dentre as 10 (dez) perguntas a partir da quinta até a sétima questão foram questionados sobre a quantidade, qualidade e recurso pedagógico dinâmico em sala de aula. A maioria das respostas dadas, incluíram desde a quantidade e qualidade dos slides, se os mesmos têm sido relevantes e para o desenvolvimento das aulas. Esse recurso segundo os resultados, no que compete à quantidade dos slides, em sua maioria de $56,7 \%$ afirmam ser suficientes para o desenvolvimento do ensino em sala de aula, 31,3\% demonstram que são excessivos, e somente $11,9 \%$ relatam ser poucos para a aprendizagem em seus cursos.

Entretanto, quando direcionamos sobre a qualidade dessa ferramenta e sua clareza, objetividade dos conteúdos apresentados pelos professores percebe-se no total de respostas, um resultado próximo do objetivo da problemática levantada em nossa pesquisa. Visto que, entre os discentes, 41,8\% relatam ser adequados para a aprendizagem, e 37,3\% parcialmente adequados, 10,4\% poucos adequados, $7,5 \%$ bastante adequados e $3 \%$ inadequados. 


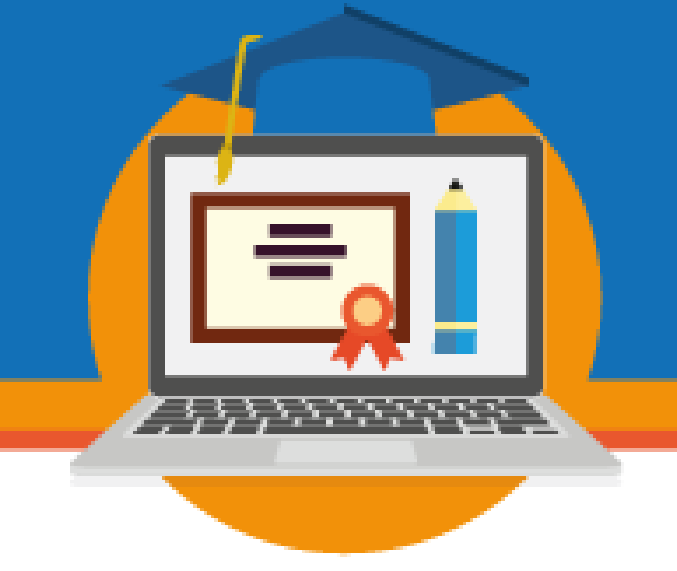

Com isso, os resultados de adequados e parcialmente adequados estão muito próximos, corroborando ao nosso olhar sobre esse recurso didático, o qual tem relevância para novas discussões e melhoria das metodologias aplicadas em sala de aula.

A forma com que usamos a tecnologia e sua dinamicidade para o ensino dos discentes do ensino superior, e em especial, em cursos de tecnologia para a investigação dessa problemática, foi muito importante para chegarmos a esses resultados. Observa-se que na questão oitava é possível ver claramente percentuais bem significativos para nossas discussões, pois o "uso de slides quanto aos objetivos do curso durante as aulas" são de que 40,3\% parcialmente adequados, $37,3 \%$ adequados, $11,9 \%$ bastantes adequados, $9 \%$ pouco adequados e $1,5 \%$ inadequados.

Os objetivos para a apresentação dos conteúdos em sala de aula, por meio dos recursos tecnológicos "slides" mesmo na área da informática tem deixado muitos discentes com opiniões bastante diversas, porque muitas vezes não se tem o aproveitamento completo da totalidade das ferramentas, para obter-se a disponibilidade aproveitável para o meio educacional.

No entanto, foi possível identificar que temos uma aceitação significativa, mas que ainda falta algo a ser questionado e melhorado sobre esse recurso didático em sala de aula. Segundo os discentes, os professores estão explorando adequadamente esse recurso slides como meio pedagógico, como podem ser observados nos números da pesquisa, 64,2\% responderam ( $\operatorname{sim}$ ) e $35,8 \%$ disseram (não).

Há de convir que existe uma aceitação entre esses alunos (as), para que as aulas tenham uma diversidade e dinâmicas metodológicas, e assim, enfatiza-se a necessidade de aprimoramento visando a melhoria de um ensino de qualidade.

Em síntese, diante dos resultados obtidos na questão descritiva para que os discentes pudessem expressar suas opiniões e de alguma forma sinalizar a nossa análise, existe ainda, um complemento dos dados que necessitamos para concluir os questionamentos iniciais desta investigação. E dessa maneira, como afirma Morin (2010, p.42): “[...] é preciso que o professor 


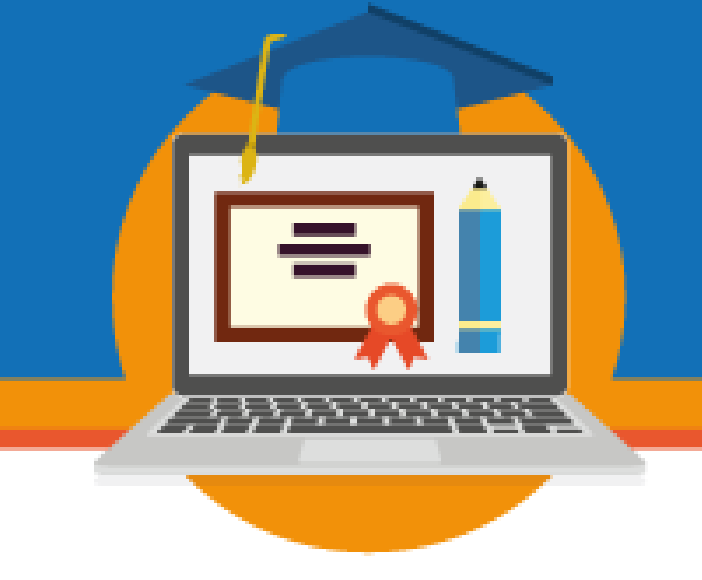

se conscientize da importância de se familiarizar com a cultura digital para que, a partir da experiência [...] possa pensar em práticas pedagógicas para aplicar com seus alunos no âmbito escolar", pois estamos em constante evolução educacional e tecnológica.

Contudo, em mais de $80 \%$ de análise das respostas observa-se uma aceitação desse recurso em sala de aula, mas é importante lembrar que ainda pode ser melhorado para que essas aulas sejam mais dinâmicas. Como afirma Dussel (2010, p.62), “las tecnologías en el ámbito escolar como los cambios en los diseños curriculares, la definición precisa de los requerimientos de formación para los docentes, así como los modos en que los alumnos incorporan (usan, resignifican y transforman) las TICs en su vida escolar y en sus vidas".

A articulação feita entre o planejar e executar nas aulas do ensino superior, por meio dos slides como meio didático ao ser levantado em nossa problemática e afirmado com a aplicação do questionário online aos discentes, foi respondido com pontos bem relevantes. Dessa forma, ao analisar os resultados obtidos nas Universidades crê-se que o recurso didático em conjunto com a tecnologia é importante em sala de aula, mas deve ser aperfeiçoado, para que possamos melhorar o aproveitamento dessas ferramentas metodológicas.

\section{CONSIDERAÇÕES FINAIS}

A pesquisa em suma teve sua relevância por estarmos inseridos nas instituições que ofertam curso de tecnologia, tanto a distância como presencial dentre a licenciatura e bacharelado, e também, efetivar as ações docentes em sala de aula e na coordenação pedagógica. Assim, em nossas discussões sobre essa prática docente e as mediações pedagógicas é que surge a problemática sobre esses recursos didáticos, nesse caso os slides nas aulas do ensino superior.

Dessa maneira, buscamos pela aplicação de um questionário online aos discentes das duas universidades UNEB e UFGD que pode nos mostrar que os docentes estão utilizando esse recurso, e como está sendo a satisfação dessa prática em sala de aula. Ao pensarmos que hoje 


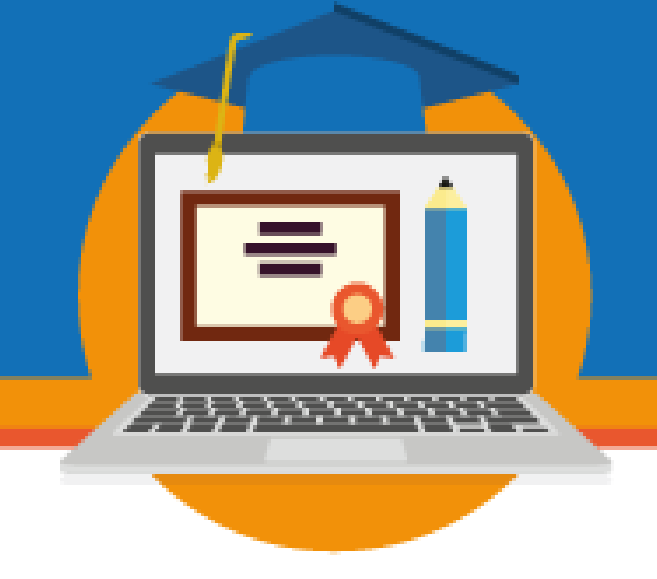

educação e tecnologia estão caminhando juntas para o enriquecimento da nossa docência em sala e ações pedagógicas na educação superior.

E esses resultados obtidos pelos discentes foram relevantes, ao que compete a essa ferramenta slide para sua mediação pedagógica ao ensino. Ao afirmar-se pela sua maioria pelos gráficos e suas porcentagens, eles acreditam na importância dessa ferramenta, mas ainda falta um aproveitamento efetivo, ao considerar muitas vezes que o slide não é utilizado da melhor forma.

Por fim, ao aprimorar essas questões e as metodologias docentes no ensino superior, ainda falta uma dinâmica e uma afinidade com a tecnologia, e mesmo investigando essas ações em cursos da área tecnológica. Sendo assim, as respostas dos discentes foram variadas desde a qualidade, a quantidade, os objetivos a serem alcançados na prática pedagógica, e ao sairmos um pouco desse ponto de que o slide, esse recurso somente serve para exposição de conteúdo.

Concluímos que esses estudantes gostam da utilização dessa ferramenta em aulas, mas questionam a falta de dinâmica e criatividade dos docentes, pois poderiam usar mais vídeos, imagens, uma leitura compartilhada. E essa participação, por meio dessa ferramenta seria mais proveitosa, tanto pela participação do professor como também direcionada ao aluno durante a aprendizagem, e não somente uma exposição desse conteúdo de forma estática. Portanto, por estarmos em uma prática de mediação e não somente de transmissão de conhecimento, que acreditamos ser relevante as discussões apresentadas e o levantamento dessa problemática em nossa pesquisa e os resultados alcançados do uso desse recurso.

\section{REFERÊNCIAS}

CELLARD, André. A análise documental. In: POUPART, Jean. A Pesquisa Qualitativa: enfoques epistemológicos e metodológicos. Petrópolis: Vozes, 2008, p. 295-316. 
DUSSEL, I. VI Foro Latino americano de Educación; Educación y nuevas tecnlogias: lós desafios pedagógico ante el mundo digital. Buenos Aires: Santillana, 2010.

GIL, A. C. Métodos e Técnicas de Pesquisa Social. 6. ed. São Paulo: Atlas, 2009. 200 p.

KENSKI, V. M. Educação e Tecnologias o novo ritmo da informação. Editora Papirus. Campinas, SP, $8^{\circ}$ edição, 2012.

LÉVY, P. Tecnologias da Inteligência: o futuro do pensamento na era da informática. Tradução de Carlos Irineu da Costa. Rio de Janeiro: ED. 34, 1993.

MENEGAZ, E; S. Tecnologias Digitais no Programa Ensino Médio Inovador: Práticas e Perspectivas. Dissertação (Mestrado) - Universidade do Estado de Santa Catarina, Centro de Ciências Humanas e da Educação, Programa de Pós-Graduação em Educação, Florianópolis, 2016.

MINAYO, M. C. de S. (Org.). Pesquisa social: teoria método e criatividade. $17^{\mathrm{a}}$ ed. Petrópolis, RJ: Vozes, 1994. 80p.

MORGADO, José C. O Estudo de Caso na Investigação em Educação. $1^{\mathrm{a}}$ ed., Santo Tirso Portugal: De Facto Editores, 2012.

MORIN, E. Os setes saberes necessários à educação do futuro. Tradução de Catarina Eleonora F. Silva e Jeanne Sawaya. São Paulo: Cortez, 2000.

RAMPAZZO, L. Metodologia científica: para alunos dos cursos de graduação e pósgraduação. 3. ed. São Paulo: Loyola, 2005.

RICHARDSON, R. J. Pesquisa social: métodos e técnicas. 3. ed. São Paulo: Atlas, 2008. 334 p.

SASS, O.; MINHOTO, M. A. P. Indicadores e educação no Brasil, a avaliação como tecnologia. In: Constelaciones - Revista de teoria Crítica. N.2 Dez./2012. Disponível em: <www.constelaciones-rtc.net/02/02_11.pdf>. Acesso em: 07 dez. 2017. 


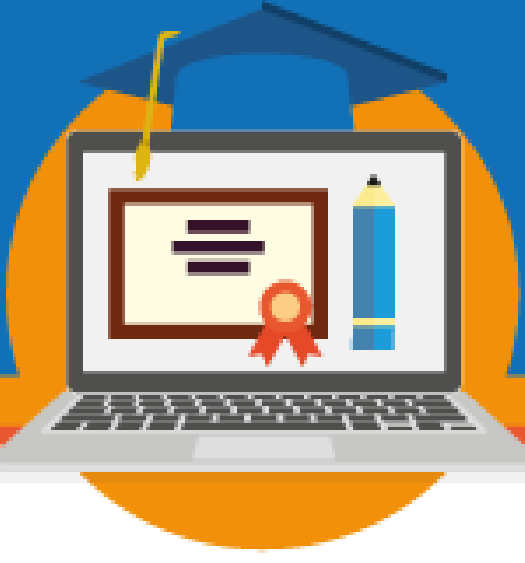

SEVERINO, A. J. Metodologia do Trabalho Científico. 23. ed. São Paulo: Cortez. 2007.

SOUZA, A. G.; LINHARES, R. N. Entre a teoria e a prática: um Olhar sobre as tecnologias da Informação e da comunicação (tics) na formação de professores. Revista Contrapontos Eletrônica, Vol. 12 - n. 1 - p. 27-36 / jan-abr. 2012.

TEIXEIRA, E. As três metodologias: acadêmica, da ciência e da pesquisa. $2^{\mathrm{a}}$ ed. Petrópolis, RJ: Vozes, 2006. 203 p. 